\section{BÀN LUÂN}

Kết quả của chúng tôi cho thấy tỷ lê đáp ứng chung của phác đồ là $58,9 \%$, trong đó tỷ lệ đáp ứng hoàn toàn là $10,7 \%$, tỷ lệ đáp ứng ở nhóm bệnh nhân điều trị phác đồ bước 1 và bước 2 lần lượt là là $67,5 \%$ và $37,5 \%$. Kết quả của chúng tôi cao hơn nghiên cứu của Zhang (2015) với tỉ lệ đáp ứng bước 1 là $57,7 \%$ đồng thời cũng cao hớn nghiên cứu của Chen và cộng sự (2020) với lệ đáp ứng toàn bộ là $49 \%$ trong đó tỉ lệ đáp ứng toàn bộ của điều trị tại bước 1 , bước 2 , và bước 3 lần lượt là 53\%, 26,7\%, 26,7\% [5] [7].

Có sự khác biệt này có thể là bệnh nhân trong nghiên cứu của tác giả Zhang và Chen bao gồm cả nhóm bệnh nhân di căn não, đây là nhóm bệnh nhân có tỉ lệ đáp ứng điều trị kém hơn so với những bệnh nhân có vị trí di căn khác.

Trong nghiên cứu của chúng tôi, thời gian sống thêm không bệnh tiến triển trung bình là 6,97 tháng, ngắn nhất là 3 tháng, dài nhất là 18 tháng. Trung vị sống thêm không tiến triển là 7,0 $\pm 0,5$ tháng. Kết quả của chúng tôi thấp hơn nghiên cứu của Zhang và cộng sự (2015) với PFS là 7,8 tháng [5]. Tương tự, nghiển cứu của Chen và cộng sự 2020 với trung vị PFS là 8,4 tháng [7]. Điều này có thể giải thích do các bệnh nhân trong nghiên cứu của chúng tôi có tỉ lệ di căn tạng lớn hơn, tî lệ di căn xương và tái phát tại chố tại vùng thấp hơn. Đây là một trong những yếu tố tiên lượng xấu ảnh hưởng đến kết quả điều trị.

Đánh giá về độc tính của phác đồ, nghiên cứu của chúng tôi thường gặp chủ yếu là độc tính độ 1, 2. Các độc tính thường gặp là ha bạch cầu hạt $(63,5 \%)$, hạ huyết sắc tố $(50 \%)$, hạ tiểu cầu $(26,8 \%)$, rụng tóc (46,4\%), nôn và buồn nôn (51,7\%).

\section{KẾT LUẬN}

Sự phối hóa chất dựa trên nền tảng platin đem lại hiệu quả về tỉ lệ đáp ứng và thời gian sống thêm bệnh không tiến triển cao cho bệnh nhân UTV BBAT tái phát hoặc di căn. Tuy nhiên cần đánh giá và theo dõi sát độc tính của phác đồ trong quá trình điều trị.

\section{TÀI LIỆU THAM KHẢO}

1. CA: A Cancer Journal for Clinicians. American Cancer Society Journals, $<$ https://acsjournals.onlinelibrary.wiley.com/journa 1/15424863>, accessed: 30/05/2021.

2. Kaya V., Yilldirim M., Yazici G. và cộng sự. (2018). Effectiveness of Platinum-Based Treatment for Triple Negative Metastatic Breast Cancer: a Meta-Analysis. Asian Pac J Cancer Prev APJCP, 19(5), 1169.

3. Brouckaert 0 ., Wildiers H., Floris G. và công sự. (2012). Update on triple-negative breast cancer: prognosis and management strategies. Int J Womens Health, 4, 511-520.

4. Dent R., Trudeau M., Pritchard K.I. và cộng sư. (2007). Triple-negative breast cancer: clinical features and patterns of recurrence. Clin Cancer Res Off J Am Assoc Cancer Res, 13(15 Pt 1), 4429-4434.

5. Zhang J., Fan M., Xie J. và cộng sự. (2015). Chemotherapy of metastatic triple negative breast cancer: Experience of using platinum-based chemotherapy. Oncotarget, 6(40), 43135-43143.

6. Eisenhauer E.A., Therasse P., Bogaerts J. và cộng sự. (2009). New response evaluation criteria in solid tumours: Revised RECIST quideline (version 1.1). Eur J Cancer, 45(2), 228-247.

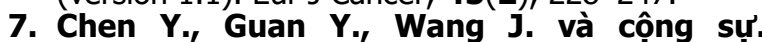
(2020). Platinum-based chemotherapy in advanced triple-negative breast cancer: A multicenter real-world study in China. Int J Cancer, 147(12), 3490-3499.

\title{
BÁO CÁO CA BỆNH: HộI CHỨNG EKBOM
}

\section{Phùng Thị Thúy Hằng ${ }^{1}$, Lê Việt Sơnn ${ }^{1}$, Nguyễn Thị Thanh Tâm¹, Nguyễn Thị Phương Loan ${ }^{2}$, Vũ Văn Hoài ${ }^{2}$, Nguyễn Thị Phương ${ }^{3}$, Nguyễn Văn Giáp ${ }^{3}$, Phạm Văn Thích ${ }^{3}$, Bùi Văn $\mathrm{San}^{3}$}

\section{TÓM TẮT}

\author{
${ }^{1}$ Bênh viện Bạch Mai \\ ²Viện Sức khoẻ Tâm thần, Bệnh viện Bạch Mai \\ ${ }^{3}$ Đại họ Y Hà Nội \\ Chịu trách nhiệm chính: Bùi Văn San \\ Email: buivansan@hmu.edu.vn \\ Ngày nhận bài: 16.8 .2021 \\ Ngày phản biên khoa hoc: 14.10.2021 \\ Ngày duyệt bài: 25.10 .2021
}

Bệnh nhân nữ 53 tuổi, vào viện vì: Tổn thương mắt - luôn cho rằng có những côn trùng cắn trên da. Bệnh biểu hiện khoảng 03 năm nay, bênh nhân mô tả nhìn thấy "con ghẻ" màu trắng hình dạng như hạt gạo có chân bò khắp người bệnh nhân. Bệnh nhân đi khám, điều trị chuyên khoa Da Liễu nhiều nơi nhưng tình trạng trên không đõ. Khoảng 03 tháng nay bệnh nhân cảm giác con này thường xuyên bò vào tai vào mũi, vào mắt cắn ở trong mắt, bệnh nhân đi khám và điêu trị tại Bệnh viên mắt TW, khoa Mắt Bệnh viện Bạch Mai, được làm xét nghiệm, khám lâm sàng chẩn đoán: viêm củng giác mạc hoại tử - đái tháo đường - 
tăng huyết áp. Trong quá trình điều trị bệnh nhân thường xuyên dùng bông cồn chấm lau mắt, dung kim lẩy da và kết giác mạc với mục đích bắt ghẻ côn trùng chui vào mắt, thườing xuyên tự dùng thuốc không theo chỉ định, bệnh nhân còn than phiền nhiều các biểu hiện trên mời hội chẩn chuyên khoa Tâm thần chẩn đoán theo dõi Rối loạn cơ thể hóa/ Viêm loét giác mạc củng mạc hoại tử - Tăng huyết áp - đái tháo đường. Bệnh nhân được điều chỉnh chế độ ăn, thăm khám và chăm sóc mắt, thuốc Fluvoxamine $200 \mathrm{mg} /$ ngày và Quetiapine $400 \mathrm{mg} / \mathrm{ngày}$. Sau 15 ngày điều tri bệnh thuyên giảm đước ra viện và hẹn khám lại sau 1 tháng.

Tư khoá: Hôi chứng Ekbom, xâm nhiễm ký sinh trùng, hoang tưởng nghi bệnh, viêm hoại tử nhãn cầu, tự gây tổn thương mắt,

\section{SUMMARY}

\section{CASE REPORT: EKBOM SYMPTOMS}

A 53-year-old female patient, admitted to the hospital because of eye damage, always believes that there are insect bites on her skin. The disease has been present for about 3 years, the patient described seeing a white "scabies" shaped like a rice grain with legs crawling all over the patient's body, the patient said that he had gone to many places for dermatology and treatment, but the above condition did not improve. About 3 months ago, the patient noticed that this insect often crawled into the ear, into the nose, into the eye biting in the eye, the patient went for examination and treatment at the Central Eye Hospital, the Eye Department of Bach Mai Hospital, was tested. Her diagnosis: necrotizing scleritis diabetes - hypertension. During the course of treatment, patients often use antiseptic cotton (alcohol) to wipe their eyes, use needles to prick the skin and conjunctival conjunctiva for the purpose of catching insect mites entering the eyes, often selfadministering drugs not prescribed. Patients also complained of many of the above symptoms, invited to consult a the Psychiatrist's department to diagnose Somatization disorder / necrotizing scleritis Hypertension - diabetes. Patients were adjusted to diet, examination and eye care, Fluvoxamine $200 \mathrm{mg} /$ day and Quetiapine $400 \mathrm{mg} /$ day. After 15 days of treatment, the disease was in remission and was discharged from the hospital and scheduled to be reexamined after 1 month.

Key words: Ekbom syndrome, parasitic infections, delusional suspected disease, necrotizing scleritis, selfinjurious to the eye

\section{I. ĐĂT VẤN ĐỀ}

Hội chứng Ekbom (Ekbom's syndrome: ES) có thể được gọi là hoang tưởng bị nhiễm ký sinh trùng, chứng sợ ký sinh trùng xâm nhập da hoặc chứng sợ các loại bọ bò trên da. Những thuật ngữ này đã được sử dụng để mô tả một nhóm các rối loạn tâm thần đặc trưng bởi niềm tin kì quái và lặp đi lặp lại rằng cơ thể của một người bị xâm nhiễm bởi ký sinh trùng, côn trùng, giun, sinh vật nhỏ hoặc thậm chí các vật thể (như là sợi, hạt, tinh thể; còn gọi là 'bệnh Morgellons'), trong trường hợp không có bất kỳ bằng chứng khách quan nào ủng hộ niềm tin đó. ${ }^{1}$

Bằng chứng dịch tể học cho thấy rằng $\mathrm{ES}$ là một tình trạng tương đối phổ biến với tỷ lệ nữ /nam dao động từ 2: 1 đến 3: 1, tuy nhiên có thể được điều trị bởi các bác sĩ chuyên khoa khác nhau, tình trạng bệnh này thường không được đánh giá chính xác ở các cơ sở tâm thần. Hội chứng này thường mắc ở các đối tượng trung niên hoặc cao tuổi. Tỷ lệ hiện mắc được ước tính từ $0,18-4,2$ trên 100.000 người, với tỷ lệ mắc là 1,9 trên 100.000 , tuy nhiên, sự dao động của nó rất rộng: như ở Vương quốc Anh, tỷ lệ mắc bệnh ước tính là khoảng 4,9 phần triệu. ${ }^{2}$

James Harrington (1611-1677), nhà lý luận chính trị và học giả người Anh, tranh luận với Lyell (Bác sĩ da liễu) về triệu chứng rằng mồ hôi của anh biến thành ruồi và đôi khi là ong và các loài côn trùng khác, là biểu hiện đầu tiên được ghi nhận của chứng hoang tưởng ký sinh trùng.

Năm 1938, Ekbom công bố một báo cáo trường hợp trên tạp chí Acta Psychiatrica et Neurologica Scandinavica - Praeseniler Dermatzooenwahn - báo cáo 8 bệnh nhân hoang tưởng rằng họ bị nhiễm ký sinh trùng trên $\mathrm{da}^{3}{ }^{3}$

Trong quá trình làm việc thực hành lâm sàng chúng tôi nhận thấy ca bệnh biểu hiện tổn thương tại mắt, da và tâm thần. Sau một thời gian điêu trị tại nhiều viện chuyên khoa, bệnh nhân được chuyển đến điều trị tại Viện Sức khỏe Tâm thần (VSKTT)- bệnh viện Bạch Mai, chúng tôi có tiếp nhận và hội chẩn chuyền khoa một số trường hợp có những triệu chứng như trên, do đó chúng tôi trình bày một ca bệnh.

\section{TRÌNH BÀY CA LÂM SÀNG}

Bệnh nhân nữ 53 tuổi, vào viện vì: Tổn thương mắt - luôn cho rằng có những côn trùng cắn trên da

Bênh sử: Theo lời kể của bệnh nhân và em gái

Bệnh nhân có tiền sử sản nhi khoa bình thường, phát triển tâm thần, vận động như các bạn cùng lứa tuổi. Bệnh nhân không có tiền sử dùng các chất gây nghiện, không có tiền sử bệnh lý nội khoa, gia đình không ai mắc rối loạn tâm thần. Tính cách: bệnh nhân là người trâm tính, ít nói. Bênh nhân trước đây học lớp 7/10 học lực trung bình, do điều kiện gia đình khó khan nển bệnh nhân nghỉ học sớm. Bệnh nhân sau khi học xong thì ở nhà phụ giúp gia đình việc nội trợ và làm đồng ruộng. Sau đó bệnh nhân lập gia đình, ở nhà làm ruộng và làm thủ công ở nhà, có 2 người con, các con ngoan ngoãn khỏe mạnh hiện đã lập gia đình riêng. Gia đình bênh nhân hòa thuận, kinh tế gia đình trung bình, bệnh nhân 
không có mâu thuẫn với ai.

Bệnh biểu hiện khoảng 03 năm nay, bệnh nhân có người cổ hàng xóm chăn nuôi gia súc, gia cầm nhiều, thường xuyên sang nhà bệnh nhân chơi. Cùng thời gian đó, người này có biểu hiện thường xuyên ngứa chân tay, người này thường cùng nằm một chỗ với bênh nhân để xem ti vi. Sau đó bệnh nhân xuất hiện ngứa đầu vùng thái dương bên trái, bệnh nhân ban đầu cho rằng mình bị ngứa là do lây của người hàng xóm, bệnh nhân ban đầu chỉ xoa nhẹ trên da cho bớt ngứa, càng về sau mức độ ngứa càng nhiều hơn. Kèm theo đó bệnh nhẩn cảm thấy như có con gì đó bò trên da, thi thoảng cắn vào da. Bênh nhân cảm thấy bứt rứt khó chiu và mô tả nhìn thấy "con ghẻ" màu trắng hình dạng như hạt gạo có chân bò khắp người. Bệnh nhân kể đi khám chuyên khoa Da Liễu, yêu cầu bác sĩ dùng dụng cụ gắp con này ra khỏi da bệnh nhân, làm xét nghiệm, làm thủ thuật, bệnh nhân thường xuyên phải xoa, gãi khắp người để đẩy con này ra khỏi da, bệnh nhân chỉ cho mọi người "con ghẻ" này để chứng minh nhưng không có ai thấy. Bệnh nhân trong 3 năm đi khám và điều trị chuyên khoa da liễu nhiều nơi nhưng tình trạng trên không đỡ, bệnh nhân về nhà tự cách ly với người thân vì sợ lây bệnh cho người thân, đốt hết quần áo, chăn màn bàn ghế cũ. Khoảng 03 tháng nay bệnh nhân cảm giác con này thường xuyên bò vào tai vào mũi, vào mắt cắn ở trong mắt bệnh nhân, bệnh nhân đưa tay lên xoa dụi mắt nhiều, tự tra thuốc vào mắt, bệnh nhân thấy mắt đỏ nhiều, chảy dịch bệnh nhân đi khám và điều trị tại Bệnh viên mắt trung ương, sau đó bệnh nhân phát hiện tăng huyết áp, đái tháo đường. Tình trạng mắt bệnh nhân chảy dịch mủ nhiêu, mờ mắt tăng dần, hiện tại bệnh nhân chỉ phân biệt được sáng tối, đêm bệnh nhân ngủ được, mỗi khi thức dậy tình trạng khó chịu trên da, trong mắt, trong tai, trong mũi lại xuất hiện làm bệnh nhân khó chịu nhiều. Bệnh nhân được chuyển đến khoa Mắt Bệnh viện Bạch Mai, được làm xét nghiệm, khám lâm sàng chẩn đoán: viêm củng giác mạc hoại tử - đái tháo đườngtăng huyết áp. Khi vào khoa điều trị bênh nhân được tiến hành lấy xét nghiệm nuôi cấy vi khuẩn tại mắt phát hiện bệnh nhân để bông cồn trong mắt dẫn đến viêm hoại tử nhãn cầu (tự gây tổn thương mắt). Trong quá trình điều trị bệnh nhân thường xuyên dung bông cồn chấm lau mắt, dùng kim lẩy da và kết giác mạc với mục đích bắt ghẻ côn trùng chui vào mắt, thường xuyên tự dùng thuốc không theo chỉ định, bệnh nhân còn than phiên nhiều các biểu hiện trên mời hội chẩn chuyên khoa Tâm thần. Sau đó bệnh nhân được chuyển sang Viện Sức khỏe Tâm thần trong tình trạng, cho rằng trên người có nhiều "con ghẻ" bò trên người, cắn trên da, trong mắt không giải thích đả thông được, mắt phân biệt sáng tối, chảy ít dịch đục.

Tiên sử: Bản thân: Không có tiền sử rối loạn sức khỏe tâm thần

Tính cách: vui vẻ hòa đồng, không hay lo nghĩ, căng thẳng

Không có tiền sử dị ứng

Gia đình: không ai mắc bệnh tâm thần, động kinh, di truyền

Chồng và các con đi làm xa không thường xuyên ở nhà, chỉ có một mình bệnh nhân ở quê nhà.

Khám bệnh: Tâm thần: tỉnh, tiếp xúc tốt

Không rối loạn các năng lực định hướng

Cảm giác, tri giác: theo dõi ào giác xúc giác: Bênh nhân cảm thây có "con ghẻ" bò trên da, cắn trên da. Ảo giác thị giác: bệnh nhân miêu tả "con ghẻ" to bằng hạt gạo màu trắng có chân bò trên da.

Tư duy: theo dõi hoang tưởng nghi bệnh. BN cho rằng mình bị bệnh về da liểu, không chấp nhận giải thích của bác sĩ và người nhà vê bệnh và hành vi xoa da, đưa tay vào mũi vào tai, dụi mắt.

Cảm xúc: lo lắng nhiều, phàn nàn về bệnh, dễ cáu gắt khi giải thích tình trạng bệnh.

Hành vi: bị chi phối bởi hoang tưởng ảo giác, công việc lao động giảm sút, ăn ngủ kém, ít quan tâm tình dục.

Chú ý: giảm tập trung, giảm khả năng duy trì sự chú ý với các sự vật hiện tượng bên ngoài.

Trí nhớ, trí tuệ: bình thường.

Khám toàn thân: Thể trạng gầy: cao $1,55 \mathrm{~m}$, nặng $42 \mathrm{~kg}$, BMI: $17,5 \mathrm{~kg} / \mathrm{m}^{2}$

Lông tóc, móng bình thường

Các bộ phận khác:

Mắt: Bệnh nhân thị lực: phân biệt sáng tối,

2 mắt viêm loét giác mạc, củng mạc hoại tử, mắt trái loét thủng giác mạc tự bít, không khám được bán phần sau.

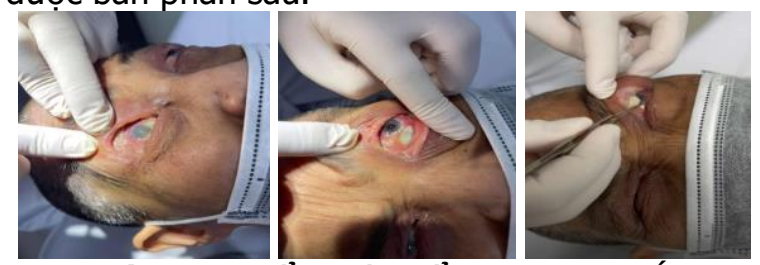

Hình 1: Biểu hiện tổn thương mắt

Tim mạch, hô hấp bình thường

Bụng không chướng, gan lách không sờ thấy

Các cơ quan khác chưa phát hiện bất thường

Chẩn đoán: Rối loạn cơ thể hóa/ Viêm loét giác mạc củng mạc hoại tử - Tăng huyết áp - đái 
tháo đường.

Cận lâm sàng: Làm các xét nghiệm cơ bản Cổng thức máu: Hồng cầu: 3.58 T/L, Hb: 111g/L Tiểu cầu: $547 \mathrm{G} / \mathrm{L}$

Bạch câu: $12.33 \mathrm{G} / \mathrm{L}$

Sinh hóa máu: Creatinin: $55 \mu \mathrm{mol} / \mathrm{L}$, ASTALT:15-12 U/L

CRP hs: $0.25 \mathrm{mg} / \mathrm{dL}$, HbA1C: $6.4 \%$

Vi sinh: HIV, HbsAg: âm tính

Toxoplasma IgG: âm tính

Kháng thể giun lươn, giun đũa chó mèo, sán

máng, sán lá gan lơn: âm tính

Cái ghẻ soi tươi: không thây kí sinh trùng

Vi khuẩn nuôi cấy định dạnh hệ thống (dịch mủ mắt): âm tính

Soi tươi tìm nấm: không thấy

Miễn dịch: Kháng thể kháng nhân, kháng dsDNA, kháng SS-A, SS-B: âm tính

Định lượng IgG, IgE, C3, C4: trong giới hạn bình thường

Siêu âm ổ bụng: Sỏi nhỏ túi mật, nang nhỏ thận phải

Cộng hưởng từ so não:

Mắt trái: thủng giác mạc và mất thủy tinh thể, giảm thể tích dịch kính, giảm kích thước nhãn câu.

Nhu mô não bình thường.

Quá trình điêuu trị: Bệnh nhân được khám, hội chuẩn chuyên khoa mắt sau đó chuyển chuyên khoa tâm thần. Tại chuyên khoa tâm thần được đánh giá về tâm thần và điều trị các triệu chứng.

Bệnh nhân được sử dụng thuốc:

Fluvoxamine $200 \mathrm{mg} / \mathrm{ngày}$ và Quetiapine $400 \mathrm{mg} / \mathrm{ngày}$.

Bệnh nhân ăn chế độ DD01 tại bênh viện

Trong quá trình điều trị bệnh nhân có những thay đổi về tình trạng tâm thần: bệnh nhân ngủ tốt hơn (7-9 tiếng/ngày), đõ than phiền về các khó chịu trên da, tần suất sử dụng các phương pháp lau mắt giảm.

Kèm theo tác động với người chăm sóc, gia đình yên tâm điều trị

Bệnh nhân được điều trị duy trì 15 ngày tiếp theo với phác đồ như trên và được ra viện, hẹn khám lại sau 1 tháng.

\section{BÀN LUÂN}

Hội chứng Eskbom là một chứng rối loạn tâm thần, trong đó các cá nhân có niềm tin dai dẳng rằng họ bị nhiễm các mầm bệnh sống hoặc không sống như ký sinh trùng, cổn trùng hoặc bo, khi khônng có biểu hiên khách quan đó. Ho thường báo cáo ảo giác xúc giác được gọi là cảm giác gần như kiến bò trên da, cảm giác giống như côn trùng bò trên hoặc dưới da.

Triệu chứng bện: Những người mắc chứng này tin rằng "ký sinh trùng, giun, ve, vi khuẩn, nấm" hoặc một số sinh vật sống khác đã gây bệnh cho họ và không thể giải thích khoa hoc để đả thông niềm tin này. Thông tin chi tiết khác nhau giữa những người mắc tình trạng này, thường biểu hiện cảm giác như kiến bò và châm chích, liên quan đến việc ký sinh trùng được cảm nhận bò lên hoặc chui vào da, đôi khi kèm theo cảm giác thực tế (đã biết như cảm giác gần như kiến bò trên da). Một số cá nhân có thể tự gây thương tích khi cố gắng loại bỏ "ký sinh trùng"; kết quả tổn thương da bao gồm trây da, vết bầm tím và vết cắt, cũng như tổn thương do sử dụng các chất hóa học và thói quen tẩy rửa ám ảnh. ${ }^{4}$

Các sự kiện như bị côn trùng cắn, đi du lịch, dùng chung quần áo, hoặc tiếp xúc với người bị nhiễm bệnh; những sự kiện như vậy có thể khiến cá nhân biểu hiện rõ hơn về các triệu chứng mà ho có thể bỏ qua trước đây. Gần như bất kỳ dấu vết nào trên da, hoặc vật thể hoặc hạt nhỏ được tìm thấy trên người hoặc quần áo của họ, đều có thể được hiểu là bằng chứng cho sự nhiễm ký sinh trừng và những cá nhân mắc bệnh thường buộc phải thu thập "bằng chứng" như vậy để trình bày cho các chuyên gia y tế. Trên bệnh nhân của chúng tôi có những triệu chứng xuất phát từ những người xung quanh (cô hàng xóm chăn bò), các diến biến tiếp xúc, phát sinh và quá trình tìm kiếm rất nhiều nơi. Thêm vào đó bệnh nhân tự giảm khó chịu gây ra những tổn thương không hồi phục ở mắt.

Hoang tưởng tương tự có thể xuất hiện ở những người thân ruột thịt - một tình trạng chung đước goi là folie à deux - xảy ra trong 15$25 \%$ trường hợp và được coi là một chứng hoang tưởng cảm ứng. ${ }^{5}$ Chúng tôi theo dõi tính chất của hoang tưởng nghi bệnh trên bệnh nhân, do quá trình các triệu chứng khó chịu ảnh hưởng đồng thời không giải thích được bởi các chuyên khoa có thể dẫn tới những cảm xúc, suy nghĩ về bệnh trên bệnh nhân này.

Nguyên nhân bênh: Nguyên nhân của hội chứng chưa được biết rõ. Nó có thể liên quan đến việc tăng dopamine trong thể vân của não, do suy giảm chức năng vận chuyển dopamine (DAT), điều chỉnh tái hấp thu dopamine trong não. Bằng chứng ủng hộ lý thuyết dopamine là các loại thuốc ức chế tái hấp thu dopamine (ví dụ như cocaine và amphetamine) được biết là gẩy ra các triệu chứng giống hội chứng này. Các điều kiện khác cũng chứng tỏ chức năng DAT bị 
giảm được biết là nguyên nhân gây ra hoang tưởng kí sinh trùng thứ cấp; những tình trạng này bao gồm "tâm thần phân liệt, trầm cảm, chấn thương sọ não, lạm dụng rượu, bệnh Parkinson và Huntington, nhiếm vi rút gây suy giảm miễn dịch ở người, thiếu sắt". Bằng chứng nữa là thuốc chống loan thần cải thiện các triệu chứng của $E S$, có thể là do chúng ảnh hưởng đến sự truyền dopamine. ${ }^{4}$

Trền bệnh nhân này chúng tôi chưa có đủ điều kiện làm những xét nghiệm chất dẫn truyền những xét nghiệm chuẩn đoán phân biệt với một bệnh cơ thể chúng tôi làm tối đa có thể trong các phương pháp sằn có tại Bệnh viện Bạch Mai

Chẩn đoán: ES được chẩn đoán khi hoang tưởng là biểu hiện chính của rối loạn tâm thần, cơn hoang tưởng đã kéo dài một tháng hoăc lâu hơn, hành vi không có gì kỳ lạ hoặc suy giảm rõ rệt, rối loạn cảm xúc, nếu có thì tương đối ngắn và hoang tưởng không thể được giải thích rõ hơn về tình trạng bệnh lý khác, rối loạn tâm thần hoặc tác động của một chất nào đó. Để chẩn đoán, cá nhân phải quy kết những cảm giác bất thường trên da là do họ bị nhiễm trùng và tin chắc rằng họ bị nhiễm kí sinh trùng ngay cả khi bằng chứng cho thây họ không bị nhiễm bệnh.

Khám, xét nghiệm để loại trừ các tình trang khác giúp xây dựng mối quan hệ tin cậy với bác sĩ; điêuu này có thể bao gồm phân tích trong phòng thí nghiệm như công thức máu, tốc độ máu lắng, CRP, phân tích nước tiểu để tìm chất độc và hormone tuyến giáp, ngoài ra còn có sinh thiết da và xét nghiệm da liễu để phát hiện hoặc loại trừ là yếu tố quyết định chẩn đoán. ${ }^{6}$

Ngoài chẩn đoán tổn thương tại mắt, các triệu chứng ban đâu chúng tôi đưa ra phù hợp với một Rối loạn cơ thể hoá (F45.0 - ICD 10) do những than phiền về triệu chứng cơ thể, tìm kiếm nhiều phương pháp thăm khám, không giải thích bằng các xét nghiệm cũng như thăm khám phù hợp với bệnh. Tuy vậy khi đánh giá kết hợp thì trên bệnh nhân này có những điểm khác: các cảm giác về ký sinh trùng là chủ yếu, các tìm kiếm và phương thức nhằm loại bỏ chúng dẫn tới những hậu quả lớn (hoại tử nhãn cầu). Chúng tôi tìm kiếm các thông tin y khoa và mạnh dạn đề xuất Hội chứng Ekbom trên bệnh nhân này.

Điêu trị: Tính đến năm 2019, chưa có bất kỳ nghiên cứu nào so sánh các phương pháp điều trị có sẵn với giả dược. ${ }^{7}$

Phương pháp điều trị chủ yếu có thể chữa khỏi và hiệu quả nhất là dùng thuốc chống loạn thần liều thấp. Risperidone là lựa chọn hàng đầu cho điều trị. Trong nhiều năm, phương pháp điều trị được lựa chọn là pimozide, nhưng nó có tác dụng phụ cao hơn so với các thuốc chống loạn thần mới hơn. ${ }^{8}$ Aripiprazole và ziprasidone có hiệu quả nhưng chưa được nghiên cứu kỹ về hội chứng Ekbom. Olanzapine cũng có hiệu quả. Tất cả đều được sử dụng với liều lượng thấp nhất có thể, và tăng dần cho đến khi các triệu chứng thuyên giảm.

Liệu pháp nhận thức hành vi (CBT) cũng có thể hữu ích. Bệnh nhân của chúng tôi được điều trị với các thuốc chống trầm cảm và an thần kinh trong đó chúng tôi chọn Fluvoxamine và Quetiapine. Cả 2 thuốc có tác dụng an dịu, liều thấp đáp ứng trên bệnh nhân tốt: ngủ tốt hơn, đõ than phiền, ít ảnh hưởng tới chuyển hoá (đái tháo đường typ2). Kèm theo bệnh nhân và người chăm sóc được chuyển chuyên khoa Tâm thần, được thăm khám, giải thích, động viên của nhân viên tại viện, sau 2 tuần các triệu chứng có thuyên giảm.

Tiên lượng: Thời gian trung bình của tình trạng này là khoảng 3 năm. Tình trạng này dẫn đến sự cô lập xã hội và ảnh hưởng đến việc làm. Có thể chữa khỏi bằng thuốc chống loạn thần hoặc bằng cách điều trị các bệnh tiềm ẩn.

Chúng tôi giữ liên lạc và hẹn khám lại bệnh nhân để đánh giá lại các triệu chứng cũng như kết quả điều trị ngoại trú.

\section{KINH NGHIỆM VÀ KIẾN NGH!}

1. Đối với những bệnh nhân có biểu hiện như trên đặt ra cho các bác sĩ cần thăm khám kỹ và hỏi bệnh sử chi tiết để phát hiện về triệu chứng cơ thể và cả triệu chứng tâm thần.

2. Khi đã phát hiện bệnh nhân không có yếu tỗ về truyền nhiễm hay ảnh hưởng bởi bệnh cơ thể thì khám và tư vấn về vấn đề tâm thần là cần thiết.

3. Quá trình điều trị bệnh nhân trên và tham khảo y văn thấy được khó khăn khi bệnh nhân không thừa nhận bệnh, không hợp tác điều trị và bệnh ảnh hưởng gia đình. Đó cũng là thách thức của bệnh đối với các bác sĩ cần tìm hiểu và nghiên cứu.

\section{TÀI LIỆU THAM KHẢO}

1. Moriarty N, Alam M, Kalus A, O'Connor $K$. Current Understanding and Approach to Delusional Infestation. The American Journal of Medicine. 2019;132(12):1401-1409.

doi:10.1016/j.amjmed.2019.06.017

2. Olivera MJ, Porras Villamil JF, López Moreno GA, Toquica Gahona CC, Paez Ardila $H$, Maldonado Lara E. Delusional infestation. Ekbom's syndrome in a 47-year-old woman. Case report. Case reports. 2017;3(2):114-125. doi:10.15446/ cr.v3n2.62754 
3. Orsolini L, Gentilotti A, Giordani M, Volpe U. Historical and clinical considerations on Ekbom's syndrome. International Review of Psychiatry. 2020;32(5-6):424-436. doi:10.1080/09540261.2020.1757306

4. Reich A, Kwiatkowska D, Pacan P. Delusions of Parasitosis: An Update. Dermatol Ther (Heidelb). 2019;9(4):631-638. doi:10.1007/s13555-019-00324-3

5. Sawant NS, Vispute CD. Delusional parasitosis with folie à deux: A case series. Ind Psychiatry J. 2015;24(1):97-98. doi:10.4103/0972-6748.160950

6. Campbell EH, Elston DM, Hawthorne JD,
Beckert DR. Diagnosis and management of delusional parasitosis. Journal of the American Academy of Dermatology. 2019;80(5):1428-1434. doi:10.1016/j.jaad.2018.12.012

7. Assalman I, Ahmed A, Alhajjar R, Bewley AP Taylor R. Treatments for primary delusional infestation. Cochrane Database Syst Rev. 2019:2019(12):CD011326.

doi:10.1002/14651858.CD011326.pub2

8. Bellanger A-P, Crouzet $J$, Boussard $M$, et al. Ectoparasitosis or Ekbom syndrome? Can Fam Physician. 2009;55(11):1089-1092.

\section{KẾT QUẢ KIỂM SOÁT GLUCOSE MÁU Ở TRẺ ĐÁI THÁO ĐƯỜNG SƠ SINH TẠI BỆNH VIỆN NHI TRUNG ƯƠNG}

\section{TÓM TẮT}

Kiểm soát glucose máu (KSGM) ở mức tối ưu là muc tiêu cơ bản để điều trị và quản lý bênh đái tháo đường. KSGM tốt cho trẻ mắc đái tháo đường sơ sinh (ĐTĐSS) giúp trẻ ngăn ngừa các biến chứng. Mục tiêu: Nhận xét kết quả KSGM ở trẻ ĐTĐSS tại bệnh viện Nhi Trung ương. Phương pháp: mô tả một loat ca bệnh. Kết quả: $94,1 \%$ bệnh nhân đột biến $\mathrm{ABCC} 8 / \mathrm{KCNJ11}$ đạt mức KSGM tốt khi điêuu trị bằng SU, 1 bênh nhân chưa phát hiên gen đôt biến đước điều trị với SU có mức KSGM ban đâu tốt, khi chuyển đổi sang insulin có mức glucose máu tốt nhưng $\mathrm{HbA} 1 \mathrm{c}$ kém. Khi điêu trị bằng insulin có $37,5 \%$ (dựa vào HbA1c), 25\% (dưa vào glucose máu) bênh nhân có đột biến gen khác đạt mục tiêu KSGM. 2/7 bệnh nhân không có đôt biến gen đã được dừng thuổc nhưng phải tái sử dụng insulin trong những đợt nhiễm trùng cấp. $100 \%$ bểnh nhân có bất thường $6 q 24$ được KSGM tốt trước khi dừng thuốc, chưa có bệnh nhân nào tái phát. Không bênh nhân nào hạ glucose máu năng, ha glucose máu không triệu chứng gặp chủ yếu ở nhóm điều trị bằng insulin.

Từ khoá: đái tháo đường sơ sinh, kiểm soát glucose máu, insulin, sulfonylurea

\section{SUMMARY \\ RESULTS OF GLYCEMIC CONTROL IN NEONATAL DEABETES MELLITUS ATNATIONAL CHILDREN'S HOSPITAL}

Glycemic control (GC) is the primary goal for the regulation and management of diabetes. Good glycemic control for children with neonatal diabetes mellitus (NDM) helps prevent complications. Objectives: Review the results of GC in NDM children at the National Children's Hospital. Method: Cases

${ }^{1}$ Trường Đại học Y Hà Nội

²Bênh viện Nhi Trung ương

Chịu trách nhiệm chính: Cấn Thị Bích Ngọc

Email: ngocctb@nhp.org.vn

Ngày nhận bài: 6.8.2021

Ngày phản biên khoa hoc: 4.10 .2021

Ngày duyệt bài: 12.10.2021

\section{Nguyễn Thị Hoài ${ }^{1}$, Cấn Thị Bích Ngọc ${ }^{2}$}

series report. Results: $94.1 \%$ of patients carrying ABCC8/KCNJ11 mutations achieved good GC levels when treated with $\mathrm{SU}$, one patient with undetected mutant genes treated with SU had good baseline blood glucose levels, when converted to insulin had good blood glucose levels but poor HbA1c. When treated with insulin, 37.5\% (HbA1c-based) and 25\% (blood-glucose-based) patients with other gene mutations reached the GMG target. 2/7 patients without genetic mutations were stopped but had to restart insulin during acute infections. $100 \%$ of patients with 6q24 abnormality had a good GC before stopping the drug, no patients had relapsed. There were no patients with severe hypoglycaemia, asymptomatic hypoglycaemia was seen mainly in insulin-treated patients.

Key world: Neonatal diabetes mellitus, glycemic control, insulin, sulfonylurea

\section{I. ĐĂT VẤN ĐỀ}

Đái tháo đường sơ sinh (ĐTĐSS) là tình trạng tăng glucose máu dai dẳng, khởi phát trước 12 tháng tuổi. Nguyên nhân gây bệnh do đột biến gen. Tỷ lệ mắc từ $1 / 90000-1 / 160000$ trẻ đẻ sống với $80 \%$ bệnh nhân mang bệnh vĩnh viễn suốt đời và $20 \%$ bênh nhân có thể khỏi bênh sau một thời gian điều trị, mặc dù có thể tái phát ở tuổi dậy thi ${ }^{1}$.

Trẻ được chẩn đoán mắc ĐTĐSS đều được điều trị bằng insulin ở thời điểm chẩn đoán. Sau đó, tuỳ thuộc kết quả phân tích gen sẽ có phương pháp điều trị khác nhau: bệnh nhân có đột biến gen mã hóa cho kênh KATP sẽ được chuyển đổi sang uống sulfonylurea (SU), bênh nhân có bất thường 6q24 sẽ được theo dõi sát để xác định thời điểm dừng thuốc, những bệnh nhân có các đột biến gen khác hoặc không có đột biến gen sẽ tiếp tục điều trị bằng insulin ${ }^{1,2}$.

Mục tiêu điêu trị ĐTĐSS là phải kiểm soát, duy trì glucose máu ở mức tối ưu nhằm ngăn ngừa các biến chứng, nhưng đồng thời phải đảm 